\title{
Silent Hypoxia in COVID-19: A Case Series
}

\author{
Thomas Fuehner ${ }^{a}, b \quad$ Isabelle Renger ${ }^{a}$ Tobias Welte ${ }^{b}$ Tobias Freundt ${ }^{a}$ \\ Jens Gottlieb ${ }^{b}$ \\ aDepartment of Respiratory Medicine, Siloah Hospital, Hannover, Germany; ${ }^{b}$ Dept of Respiratory Medicine and \\ German Centre for Lung Research (DZL/BREATH), Hannover Medical School, Hannover, Germany
}

\section{Keywords}

SARS-CoV-2 $\cdot$ Coronavirus disease 2019 . Dyspnea .

Hypoxemia $\cdot$ Hypocapnia

\begin{abstract}
Background: The coronavirus disease 2019 (COVID-19) pandemic is an ongoing global crisis challenging the worldwide healthcare systems. Many patients present with a mismatch of profound hypoxemia and few signs of respiratory distress (i.e., silent hypoxemia). This particular clinical presentation is often cited, but data are limited. Main Body: We describe dyspnea sensation as assessed by using the BORG scale in pulmonary patients admitted to the emergency room during a 4-week period and transferred to the respiratory department of Siloah Hospital, Hannover, Germany. From October 1 to November 1, 2020, 82 patients with hypoxemia defined as oxygen demand to achieve an oxygen saturation $\left(\mathrm{SpO}_{2}\right) \geq 92 \%$ were included. In 45/82 (55\%) patients, SARS$\mathrm{CoV}-2$ was detected by PCR on admission. Among non-COVID patients, exacerbation of COPD was the main diagnosis $(15 / 37,41 \%)$. All subjects rated their perceived dyspnea using the modified Borg CR10 scale. Patients in the non-COVID group suffered from more dyspnea on the modified Borg CR10 scale (median 1, IQR: $0-2$ vs. median 5, IQR: $3-6, p<$ $0.001)$. In multivariate analysis, "silent hypoxemia" as defined by the dyspnea Borg CR10 scale $\geq 5$ was independently associated with COVID-19 and presence of severe hypocapnia
\end{abstract}

with an odds ratio of 0.221 (95\% confidence interval 0.054 , $0.907, p 0.036)$. Conclusion: Among pulmonary patients with acute hypoxemia defined as oxygen demand, patients suffering from COVID-19 experience less dyspnea compared to non-COVID patients. "Silent" hypoxemia was more common in COVID-19 patients.

(c) 2021 The Author(s)

Published by S. Karger AG, Basel

\section{Introduction}

In COVID-19 patients, hypoxemia with a disproportional low sensation of dyspnea has been described. This phenomenon is referred as "silent" or "happy" hypoxemia [1-3]. The underlying mechanism of silent hypoxemia is not fully understood. "Silent" hypoxemia is not limited to COVID-19 and can be found in other respiratory disorders. The exact proportion of patients with silent hypoxemia in COVID-19 and other respiratory diseases is unknown. The aim of this study was to investigate the sensation of dyspnea in hypoxemic emergency admissions.

\section{Method}

All emergency admissions to the respiratory care unit in Siloah Hospital, Hannover, Germany, between October 1 and November 1,2020, were analyzed retrospectively. All patients received

Correspondence to:

Thomas Fuehner, fuehner.thomas@mh-hannover.de 
Table 1. Clinical characteristics

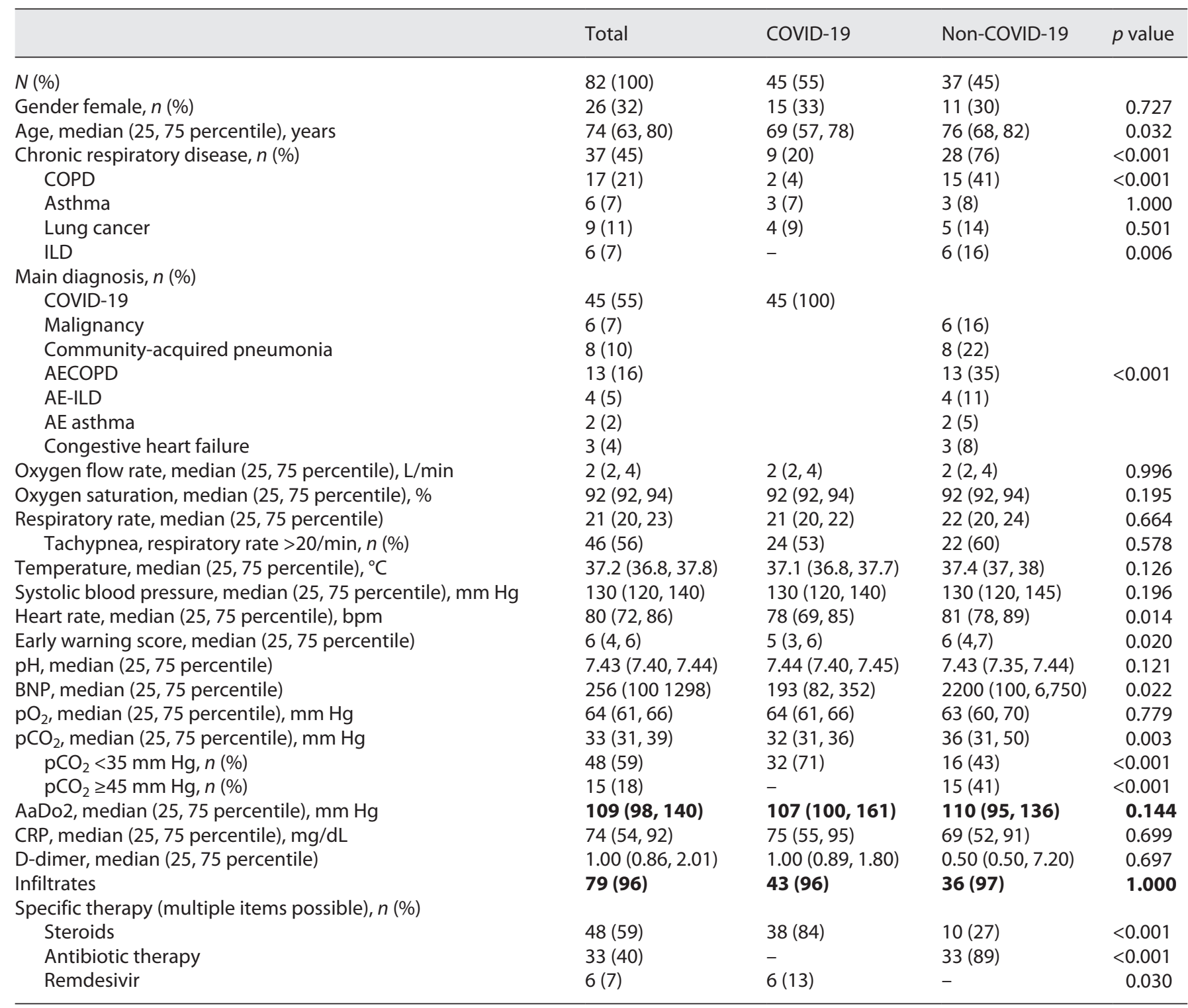

COVID-19, coronavirus disease 2019; COPD, chronic obstructive pulmonary disease; ILD, interstitial lung disease; $A E$, acute exacerbation, $\mathrm{mm} \mathrm{Hg}$, millimeters of mercury; bpm, beats per minute; $\mathrm{BNP}$, brain natriuretic peptide; $\mathrm{pO}_{2}$, partial pressure of oxygen; $\mathrm{pCO}_{2}$, partial pressure of carbon dioxide.

SARS-CoV-2 PCR testing on admission. Patients with hypoxemia defined as supplementary oxygen demand to achieve an oxygen saturation $\left(\mathrm{SpO}_{2}\right) \geq 92 \%$ in the first $24 \mathrm{~h}$ after admission were included. Vital signs were recorded, and the national early warning score (NEWS-2) was used for monitoring [4]. Oxygen demand was titrated by capillary blood gas analysis [5]. Subjects rated their perceived dyspnea using the modified Borg CR10 scale in license [6], Agreement ID 13LX473. This scale has 12 stages from 0 to 10 including 0.5. Numbers on this scale are related to a description of dyspnea during exertion. Demographics, chronic conditions (cancer, diabetes mellitus, hypertension, chronic respiratory disease, and obesity), signs and symptoms, including fever, cough, anosmia, ageusia, dyspnea, and oxygen saturation, and results of blood gas analysis were analyzed. The study was performed in accordance with the ethical guidelines of the 1975 Declaration of Helsinki and the institutional review board.

\section{Statistics}

Continuous variables were described as median and 25 and $75 \%$ quartiles. Categorical variables are presented as $n(\%) \cdot \chi^{2}$ test or 
Fisher's exact test for categorical variables if appropriate and Student's test for metric variables after testing for normal distribution to compare groups were used. A logistic regression model was fitted with a Borg CR10 scale of $\geq 5$ as the categorical outcome. Variables included were identified by a $p$ value of $<0.1$ in univariate analysis.

\section{Results}

During the study period, 82 patients were included. In 45/82 (55\%) patients, SARS-CoV-2 was detected by PCR on admission. In 9 out of 45 (20\%) of COVID-19 patients, a chronic lung disease was present compared to $28 / 37(76 \%)$ patients from the non-COVID group (Table 1). Two out of 37 (5\%) patients in the non-COVID group were using domiciliary long-term oxygen treatment prior to hospitalization. Among non-COVID patients, the majority $(15 / 37,41 \%)$ suffered from acute exacerbation of COPD, followed by community-acquired pneumonia $(8 / 37,22 \%)$. More patients in the non-COVID had a $\mathrm{pCO}_{2} \geq 45 \mathrm{~mm} \mathrm{Hg}$. No COVID-19 patient was hypercapnic. Dyspnea rated by the Borg CR10 scale was lower in the COVID-19 group, including those with chronic lung disease (Fig. 1). All but 1 non-COVID-19 patient $(98 \%)$ had a Borg CR10 scale of $<5$. There was no difference in hospital length of stay (median $10 \mathrm{vs.}$ 8 days, $p=0,189$ ), ICU admission (7/45 vs. 8/37, $p=$ $0.48)$, invasive ventilation ( $2 / 45$ vs. $2 / 37, p=1.0)$, or mortality $(6 / 45$ vs. $2 / 37, p=0.28)$ between COVID and non-COVID patients. In multivariate analysis, silent hypoxemia as defined by the dyspnea Borg CR10 scale $\geq 5$ was independently associated with COVID-19 and presence of severe hypocapnia with an odds ratio of 0.221 (95\% confidence interval $0.054,0.907, p 0.036$ ) (Table 2).

\section{Discussion}

To our knowledge, this is the first series which systematically analyzes the sensation of dyspnea in COVID-19 patients compared to patients with other respiratory diseases. Patients with COVID-19 had a higher dyspnea sensation as assessed by the BORG scale when the oxygen partial pressure was similar.

Dyspnea as shortness of breath is frequently reported in community-acquired pneumonia and COPD exacerbations in $75 \%$ and $78 \%$, respectively $[7,8]$. Docherty et al. [9] reported in a large observational cohort of 20,133 hospital admissions with COVID-19 shortness of breath

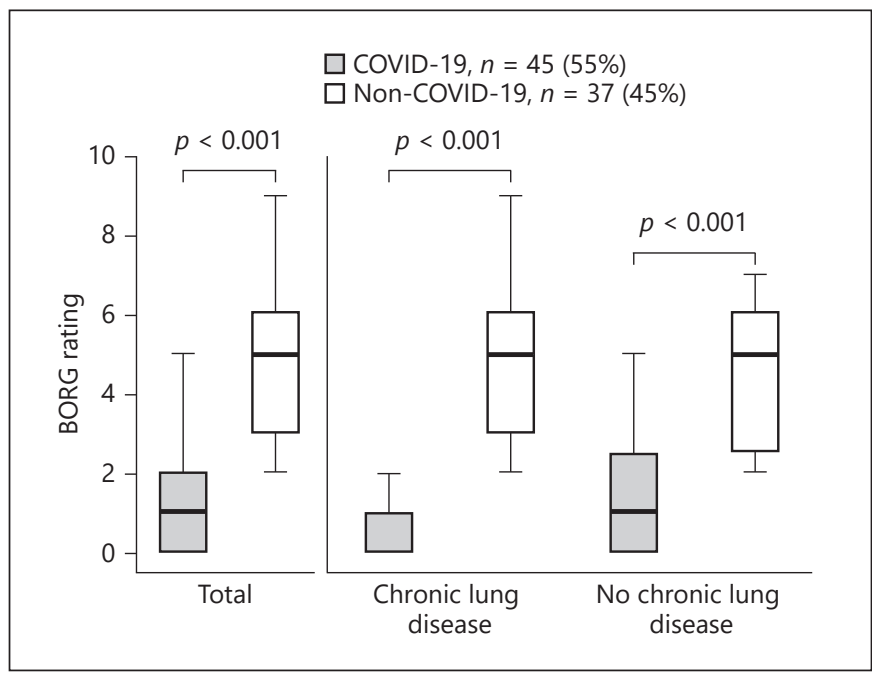

Fig. 1. Dyspnea rated by using the Borg CR10 scale in emergency admissions.

in $71 \%$. In contrast and similar to our results, in $1,712 \mathrm{CO}-$ VID-19 inpatients (two-thirds with pneumonia), 65\% did not complain of a shortness of breath at admission [10]. Unfortunately, these publications did not use an exact definition of breathlessness or did not objectively rate dyspnea.

Hypoxemia in COVID-19 is caused by intrapulmonary shunts, loss of lung perfusion regulation, intravascular microthrombi, impaired diffusion capacity, and preservation of lung mechanics [11-14]. Interestingly, the respiratory compensation mechanisms differ significantly according to the underlying lung pathology. Patients with COVID-19 and hypoxemia tend to compensate by hyperventilation and are usually hypocapnic as confirmed in our study. This respiratory compensation mechanism seems to be similar to communityacquired pneumonia or interstitial lung diseases. In both entities, dyspnea is a major symptom. Recently, hypocapnic hypoxemia without dyspnea was thought to be caused by right-to-left intrapulmonary shunt in COVID-19 [14, 15].

Hypoxemia has a limited correlation with the sensation of breathlessness while dyspnea is more correlated with hypercapnia $[16,17]$. "Silent hypoxemia" in COVID-19 may be caused by changes in the respiratory control system. Angiotensin-converting-enzyme 2 receptors are widely expressed in the nasal mucosa as well as in carotid bodies, where oxygen chemoreceptors for regulation of respiration are located. Another example of 
Table 2. Multivariate analysis

\begin{tabular}{|c|c|c|c|c|c|c|}
\hline \multicolumn{7}{|l|}{ BORG $\geq 5$} \\
\hline COVID-19, n (\%) & 78 & & & & & \\
\hline No & $36(46)$ & $21(58)$ & $15(42)$ & (Ref) & (Ref) & (Ref) \\
\hline Yes & $42(54)$ & $1(2)$ & $41(98)$ & 0.007 & $0,000-0.199$ & 0.004 \\
\hline Chronic lung disease, $n(\%)$ & 78 & & & & & \\
\hline No & $41(53)$ & $5(12)$ & $36(88)$ & (Ref) & (Ref) & (Ref) \\
\hline Yes & $37(47)$ & $17(46)$ & $20(54)$ & 0.705 & $0.038-13.206$ & 0.815 \\
\hline $\mathrm{pH}<7.35, n(\%)$ & 78 & & & & & \\
\hline No & $68(87)$ & $15(22)$ & $53(78)$ & (Ref) & (Ref) & (Ref) \\
\hline Yes & $10(13)$ & $7(70)$ & $3(30)$ & 95.816 & $1.744-5,263-453$ & 0.026 \\
\hline No & $25(32)$ & $16(64)$ & $9(36)$ & (Ref) & (Ref) & (Ref) \\
\hline Yes & $53(68)$ & $6(11)$ & $47(89)$ & 1.391 & $0.060-32.408$ & 0.837 \\
\hline Respiratory rate, median ( 25,75 percentile) & 78 & $24(21,28)$ & $21(20,22)$ & 1.271 & $0.968-1.669$ & 0.084 \\
\hline Heart rate, median $(25,75$ percentile $)$ & 78 & $86(78,90)$ & $80(71,85)$ & 1.086 & $0.983-1.199$ & 0.105 \\
\hline Early warning score, median $(25,75$ percentile) & 78 & $6(5,7)$ & $5(3,6)$ & 1.060 & $0.448-2.507$ & 0.894 \\
\hline AaDo 2 , median $(25,75$ percentile $)$ & 78 & $124(110,141)$ & $102(97,150)$ & 0.936 & $0.785-1.116$ & 0.461 \\
\hline $\mathrm{O}_{2}$ flow rate, median $(25,75$ percentile) & 78 & $3(2,4)$ & $2(2,4)$ & 6.214 & $0.052-737.097$ & 0.453 \\
\hline
\end{tabular}

Ref, reference category; COVID-19, coronavirus disease 2019; mm Hg, millimeters of mercury; $\mathrm{pO}_{2}$, partial pressure of oxygen; $\mathrm{pCO}_{2}$, partial pressure of carbon dioxide.

neural disturbances in COVID-19 is anosmia reported by one-third of patients with COVID-19 [10, 18]. Silent hypoxemia in COVID-19 deserves further study to elucidate its mechanism.

The series has potential limitation from the unicenter design with a small number of participants and a following lack of subgroup analysis. Virus variants were not screened in the clinical routine to that time. In addition, the Borg CR10 scale is a tool for measuring an individual's dyspnea during physical work. The scale is not established to rate dyspnea in patients with acute hypoxemia at rest.

\section{Conclusion}

Silent hypoxemia is more common in COVID-19 patients compared to pulmonary patients with acute hypoxemia. Further evaluation of its uniqueness and pathophysiologic mechanisms is needed.

Silent Hypoxemia in COVID-19: A

Comparison

\section{Acknowledgment}

The authors acknowledge Christina Valtin, Dept of Respiratory Medicine and German Centre for Lung Research (DZL/ BREATH), Hannover Medical School, Hannover, Germany.

\section{Statement of Ethics}

Data from the clinical routine were analyzed retrospectively. The study was performed in accordance with the Institutional Review Board, KRH Klinikum Region Hannover. All procedures, including the informed consent process, were conducted in accordance with the ethical standards of the responsible committee on human experimentation (institutional and national) and with the Helsinki Declaration of 1975, as revised in 2000.

\section{Conflict of Interest Statement}

The authors have no conflicts of interest to declare. 


\section{Funding Sources}

No funding was received.

\section{Author Contributions}

T.F. participated in the design of the study, performed the statistical analysis, conceived of the study, participated in its design and coordination, and helped to draft the manuscript. I.R. participated in the design of the study, conceived of the study, participated in its design and coordination, and helped to draft the manuscript. T.W. conceived of the study, partici- pated in its design and coordination, and helped to draft the manuscript. T.F. participated in the design of the study, conceived, and helped to draft the manuscript. J.G. participated in the design of the study, performed the statistical analysis, conceived of the study, participated in its design and coordination, and helped to draft the manuscript. All authors read and approved the final manuscript.

\section{Data Availability Statement}

The software, databases, and application/tool described in the manuscript are available for testing by reviewers.

\section{References}

1 Wu Z, McGoogan JM. Characteristics of and important lessons from the coronavirus disease 2019 (COVID-19) outbreak in China: summary of a report of 72314 cases from the Chinese Center for Disease Control and Prevention. JAMA. 2020;323:1239-42.

2 Omer SB, Malani P, Del Rio C. The COVID-19 pandemic in the US: a clinical update. JAMA. 2020 May 12;323(18):1767-8.

3 Tobin MJ, Laghi F, Jubran A. Why COVID-19 silent hypoxemia is baffling to physicians. Am J Respir Crit Care Med. 2020 Aug 1;202(3): 356-60.

4 Royal College of Physicians. National early warning score (NEWS) 2. Standardising the assessment of acute-illness severity in the NHS. 2017. Updated report of a working party.

5 German guideline organtransplanation gem. $\$ 16$ TPG: Bundesärztekammer. 2017. Available from: https://www.bundesaerztekammer.de/fileadmin/user_upload/downloads/ pdf-Ordner/RL/RiliOrgaWlOvLungeTxab20171107.pdf.

6 Borg G. Anstrengungsempfinden und körperliche Aktivität. Dtsch Ärztebl. 2004;101: A-1016/B-840/C-821.

7 Miravitlles M, Anzueto A, Legnani D, Forstmeier L, Fargel M. Patient's perception of exacerbations of COPD: the PERCEIVE study. Respir Med. 2007 Mar;101(3):453-60.

8 Marrie TJ, Lau CY, Wheeler SL, Wong CJ, Feagan BG. Predictors of symptom resolution in patients with community-acquired pneumonia. Clin Infect Dis. 2000 Dec;31(6):1362-7.

9 Docherty AB, Harrison EM, Green CA, Hardwick HE, Pius R, Norman L, et al. ISARIC4C investigators. Features of 20133 UK patients in hospital with covid-19 using the ISARIC WHO Clinical Characterisation Protocol: prospective observational cohort study. BMJ. 2020 May 22;369:m1985.

10 Brouqui P, Amrane S, Million M, Cortaredona S, Parola P, Lagier JC, et al. Asymptomatic hypoxia in COVID-19 is associated with poor outcome. Int J Infect Dis. 2021 Jan;102:233-8.

11 Lang M, Som A, Mendoza DP, Flores EJ, Reid $\mathrm{N}$, Carey D, et al. Hypoxaemia related to COVID-19: vascu-lar and perfusion abnormalities on dual-energy CT. Lancet Infect Dis. 2020;20(12):1365-6.

12 Tay MZ, Poh CM, Rénia L, MacAry PA, Ng LFP. The trinity of COVID-19: immunity, inflammation and intervention. Nat Rev Immunol. 2020;20:363-74.

13 Liu Y, Yang Y, Zhang C, Huang F, Wang F, Yuan J, et al. Clinical and biochemical indexes from 2019-nCoV infected patients linked to viral loads and lung injury. Sci China Life Sci. 2020;63:364-74.

14 Ackermann M, Verleden SE, Kuehnel M, Haverich A, Welte T, Laenger F, et al. Pulmonary vascular endothelialitis, thrombosis, and angiogenesis in COVID-19. N Engl J Med. 2020 Jul 9;383(2):120-8.

15 Mahjoub Y, Rodenstein D, Jounieaux V. Severe COVID-19 disease: rather AVDS* than ARDS? (acute vascular distress syndrome). Critical Care. 2020;24:327.

16 Kvale PA, Conway WA, Coates EO. Continuous or nocturnal oxygen therapy in hypoxemic chronic obstructive lung disease. A clinical trial. Ann Intern Med. 1980;93: 391-8.

17 Gattinoni L, Chiumello D, Caironi P, Busana M, Romitti F, Brazzi L, et al. COVID-19 pneumonia: different respiratory treatments for different phenotypes? Intensive Care Med. 2020;46(6): 1099-102.

18 Bourgonje AR, Abdulle AE, Timens W, Hillebrands JL, Navis GJ, Gordijn SJ, et al. Angiotensin-converting enzyme-2 (ACE2), SARS$\mathrm{CoV}-2$ and pathophysiology of coronavirus disease 2019 (COVID-19). J Pathol. 2020; 251(3):228-48. 